Original Research

\title{
Optimizing the DRASTIC Method for Nitrate Pollution in Groundwater Vulnerability Assessments: a Case Study in China
}

\author{
Haiyang $\mathrm{He}^{1,2,3}$, Xuguang $\mathrm{Li}^{3}$, Xiao $\mathrm{Li}^{3}$, Jian $\mathrm{Cui}^{3}$, \\ Wenjing Zhang ${ }^{1,2 *}$, Wei $\mathrm{Xu}^{4}$ \\ ${ }^{1}$ Key Laboratory of Groundwater Resources and Environment, Ministry of Education, \\ Jilin University, Changchun 130021, China \\ ${ }^{2}$ College of Environment and Resources, Jilin University, Changchun 130021, China \\ ${ }^{3}$ Shenyang Center China Geological Survey Bureau, Shenyang 110034, China \\ ${ }^{4}$ College of Water Conservancy, Shenyang Agricultural University, Shenyang 110866, China
}

Received: 6 May 2017

Accepted: 21 June 2017

\begin{abstract}
Groundwater vulnerability assessments, using DRASTIC, are important and useful tools for groundwater pollution prevention and control. The DRASTIC method, however, is not appropriate for accurate specific vulnerability assessments where nitrate concentrations are high. A new method has been developed that retains the basic structure of DRASTIC while adding or subtracting parameters, and modifying the parameter ratings and weightings. The resulting DRACILM model was used to assess vulnerability to nitrate pollution in the West Liaohe Plain and as a basis for vulnerability mapping. The accuracy, appropriateness, and reliability of the vulnerability mapping were analyzed using a group of integrated indicators, such as correlation, ANOVA F-statistics, and single-parameter sensitivity analysis. The correlation between vulnerability class and the concentration of $\mathrm{NO}_{3}-\mathrm{N}$ in the DRACILM model improved to 0.649 , which was $40.6 \%$ higher than that obtained by DRASTIC. The ANOVA F-statistic was 27.71, which indicated a lower overlap between the mean values of nitrates in the different vulnerability classes. The single-parameter sensitivity analysis revealed that land use type exhibited the highest and hydraulic conductivity the lowest effective weighting values. The vulnerability maps by DRACILM model could assist planners and government decision-makers with preliminary investigations into planning water protection projects or establishing management scenarios for water resource quality.
\end{abstract}

Keywords: groundwater vulnerability, DRACILM model, DRASTIC model, nitrate, China

*e-mail: zhangwenjing80@126.com 


\section{Introduction}

The first use of the vulnerability concept in hydrogeology was in 1970 [1]. Since the 1980s, various models and approaches for vulnerability assessment and mapping have been developed and tested [2-3]. Groundwater vulnerability can be defined by intrinsic vulnerability or specific vulnerability [4]. The intrinsic vulnerability of an aquifer is the capacity with which a contaminant introduced at the ground surface can reach and be diffused in groundwater [5]. Specific vulnerability is the vulnerability of groundwater to a particular contaminant or group of contaminants. For specific vulnerability, specific physicochemical properties from contaminants are considered [6]. In recent years, specific vulnerability has been more widely used and is more meaningful than intrinsic vulnerability, because intrinsic vulnerability assessments only consider natural factors. Therefore, intrinsic vulnerability cannot fully take into account actual pollution and the impact of human activities such as land use, model of groundwater resource yield, and groundwater quality. Land use is used in specific vulnerability assessments, and makes these results more accurate and meaningful [7].

Several approaches exist for assessing groundwater vulnerability. They can be grouped into processbased, statistical, and index-overlay methods [8-11]. Vulnerability in the index-overlay method is determined by weights, indexes, ranges, and classification. The commonly used models for groundwater vulnerability are DRASTIC, SINTACS, GOD, AVI, SYNTACS, SI, and EPIK [12-13]. The most widely used method for vulnerability evaluation is DRASTIC because of its ease of use, minimal data requirements, and clear exposition of groundwater vulnerability [14]. The method has been widely used for regional vulnerability assessments in many countries such as the USA [15-16], China [17-18], Korea [19], Canada [20], India [21], Turkey [22], Tunisia [23], South Africa [24-25], and the Ivory Coast [26].

DRASTIC, as with other similar index methods, has many disadvantages: 1) so many variables are factored into the final index that critical parameters in groundwater vulnerability may be masked by other parameters that have no bearing on vulnerability for a particular setting [27], 2) the results overestimate the vulnerability of porous media aquifers compared with aquifers in fractured media [28], and 3) the selection of the parameters is based on qualitative judgment and not quantitative studies [29-30]. Despite these disadvantages, if the method is improved by modifying factors and weights, it can be usefully deployed for continental-scale assessments of groundwater vulnerability [31]. Most of the studies which have improved the DRASTIC method according to the $\mathrm{NO}_{3}-\mathrm{N}$ pollution proposed the subtraction of factors to be included in the method or the inclusion of additional factors, e.g., land use, irrigation type and intensity, groundwater quality and pollution [32]. These studies focused on important factors of human activities that impacted groundwater vulnerability, but an important information model of groundwater resource yield was ignored, which determined the strength of human activity. The optimized model graded by geometrical interval method improved the correlation between vulnerability index and nitrate concentration to the order of 0.6698 , which was 0.4098 higher than that by the DRASTIC model [7]. By modifying and optimizing the model, the correlation coefficient between groundwater pollution risk and nitrates concentration was considerably improved and rose to $33 \%$ higher than the original method [30]. The method for groundwater vulnerability assessment has been improved significantly from a relatively simple, inconstant, and subjective survey to a comprehensive and scientific quantification evaluation. However, its results may be a little inaccurate due to the subjectivity. Little research has been conducted to overcome the subjectivity of overlay index method systematically. But some methods can be used to verify the reliability of the results, such as analytical hierarchy process (AHP), ANOVA F-statistic and sensitivity analysis, and so on [33]. Therefore, the above analysis methods were applied to verify the feasibility and accuracy of results obtained by the modified DRASTIC model, and to determine the main factors of groundwater vulnerability.

In the last 30 years, nitrate has become a major source of groundwater pollution in the West Liaohe Plain in China [34]. The main sources of nitrate are nitrogen fertilizers, domestic sewage, livestock manure, and industrial production. Because nitrate is easily transported and converted into $\mathrm{N}$ species, in some groundwater systems nitrate pollution can threaten humans and livestock as well as the environment [35]. In addition, the concentration of nitrate in groundwater is considered an indicator of groundwater quality degradation [36]. The drinking water for nearly $50 \%$ of city residents and $90 \%$ of rural residents is supplied by groundwater in the study area; for individual cities and the surrounding areas, groundwater may be the only water source. Therefore, specific research on groundwater vulnerability based on nitrate is essential to ensure the quality of groundwater and provide a scientific basis for the sustainable development of groundwater resources.

The objective of this study is to assess a modification of the DRASTIC method, which reduced several factors and added land use type and model of groundwater resource yield, especially to incorporate nitrate for a groundwater vulnerability study of the West Liaohe Plain. The modification replaces qualitative with quantitative parameters such as weightings, ratings, and classes, which could be accomplished by simple statistical methods to link the mean class of each parameter defined in the modified model to the concentration of $\mathrm{NO}_{3}-\mathrm{N}$. ANOVA F-statistic and sensitivity analysis applied to test its feasibility and accuracy. Groundwater vulnerability maps can be used to help formulate the strategies by government and planners to prevent groundwater pollution and make better use of resources. 


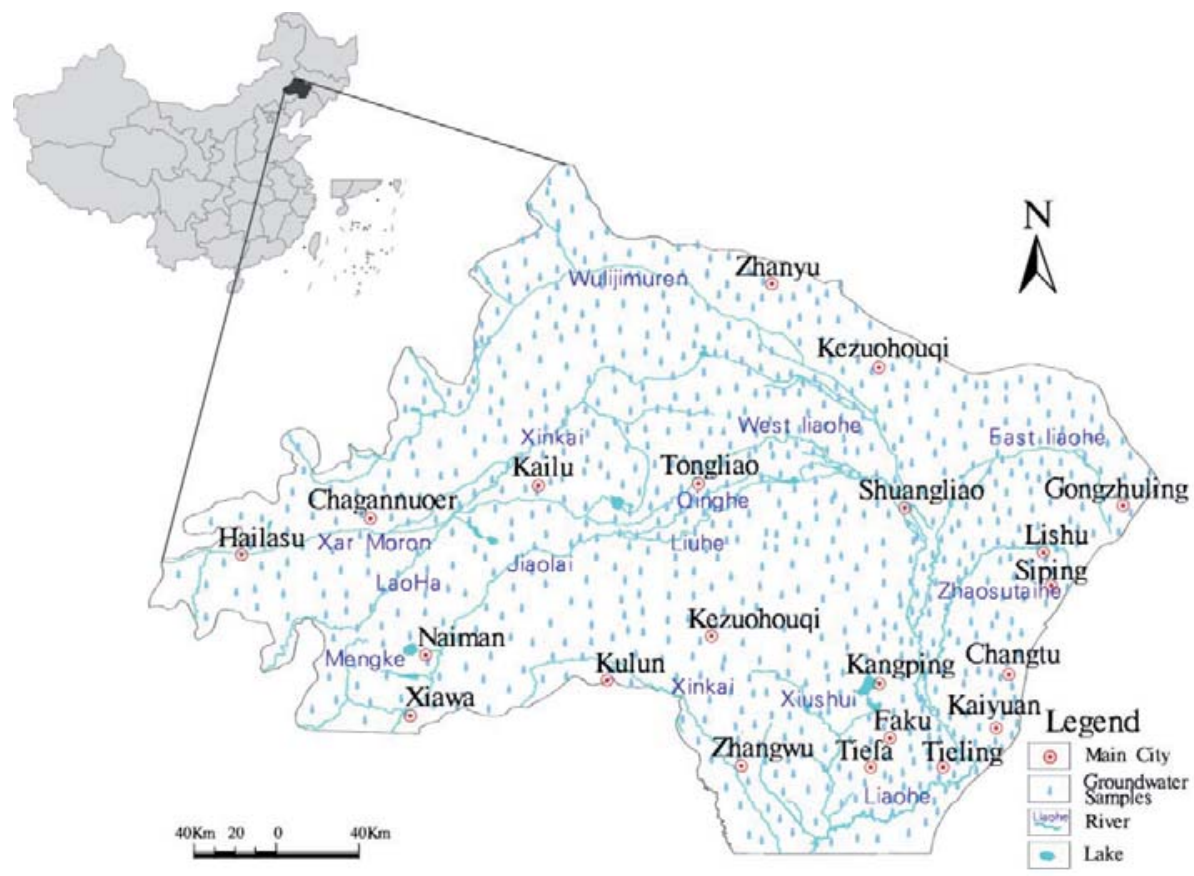

Fig. 1. Location of the study area in China.

\section{Materials and Methods}

\section{Study Area}

The study area is the West Liaohe Plain, which covers an area of approximately $8.77 \times 10^{4} \mathrm{~km}^{2}$ in northeast China, and covers parts of Liaoning, Jilin, and the Inner Mongolia provinces (Fig. 1). It is the main area of grain production in China, and is known as the "Northern Granary." The overall topography trend of the plain is high in the east, west, and north, and low in the south and center. The study area has a semi-arid, temperate, monsoon, continental climate. The average temperatures in summer and winter are $20^{\circ} \mathrm{C}$ and $-9.8^{\circ} \mathrm{C}$, respectively, and the mean annual temperature is $4.6^{\circ} \mathrm{C}$. The average annual rainfall from 1961 to 2014 was $479.5 \mathrm{~mm}$, and the average annual evaporation from 1958 to 2014 was $1,832.4 \mathrm{~mm}$. Precipitation is more concentrated in June, July, August, and September, which accounts for more than $80 \%$ of total annual precipitation. The rivers in the study area belong to the Liaohe River system; the upper part of the Liaohe system is formed by the Xiliao River, and its main tributaries are the LaoHa, Xar Moron, Wulijimuren, Jiaolai, Xinkai, and Mengke rivers. The middle of the Liaohe system is formed by the Zhaosutai, Xiushui, Lama, Qing, and Liu rivers. There are over 20 reservoirs and lakes in the region.

In the West Liaohe Plain, quaternary unconsolidated deposits, including gravels, sands, silt, and mucky silt, form a significant unconfined aquifer. The depth to groundwater is generally 1 to $10 \mathrm{~m}$, and thickness of the aquifer is 10 to $50 \mathrm{~m}$ while the center was thick and the ground thin. The hydrogeological characteristics of the area have been researched by geological teams from the Geological Survey Institute of Inner Mongolia, Jilin, and Liaoning provinces; the aquifers are divided into loose rock pore aquifers and fractured bedrock aquifers, according to the abundance of the aquifer, the pore aquifers can be divided into abundant, moderate, and short, whose water yield is higher than $10 \mathrm{~m}^{3} / \mathrm{h} \cdot \mathrm{m}$, $5-10 \mathrm{~m}^{3} / \mathrm{h} \cdot \mathrm{m}$ and less than $5 \mathrm{~m} / \mathrm{h} \cdot \mathrm{m}$, respectively (Fig. 2). The aquifer structure of the study area is single, and there are few clay layers in the aquifer and the groundwater type is mainly phreatic water. Recharge takes place by infiltration of precipitation (mainly from May to September), surface water infiltration and irrigation infiltration. Groundwater discharges toward rivers with a relatively low water level. Large areas of intense evaporation can discharge large amounts of groundwater, and human exploitation, especially for cities and towns, is also responsible for significant

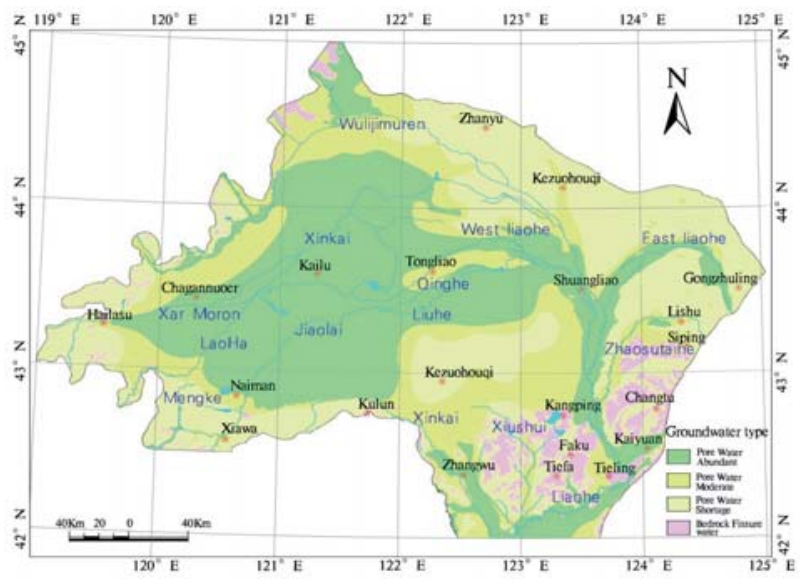

Fig. 2. Groundwater types in the study area. 
groundwater discharge. The main groundwater flow direction is from the west to the east. Based on recharge, runoff, and discharge conditions, groundwater can be divided into the rainfall infiltration-evaporation type, infiltration-runoff type, and infiltration-exploited type. In recent years groundwater has been exploited in large amounts for agricultural, industrial, animal husbandry, and domestic water use: each use accounts for $65.1 \%, 12.4 \%, 8.7 \%$, and $13.8 \%$ of the total water use, respectively. The shallow groundwater of the West Liaohe Plain has been contaminated during recent decades. The main pollution sources of groundwater in the study area are domestic, industrial, and agricultural, and domestic pollution sources are mainly domestic sewage and waste - especially in large and medium cities with a large urban population. Industrial wastewater leakage and random discharge in the ditches are the main industrial pollution sources, the phenomenon mainly occurred in the industrial parks around the cities with the rapidly development of the economy in recent years. As the plain is the main area of grain production in China, pesticides and fertilizers become the main agricultural pollution source, and nitrogen fertilizer and organic pesticide have the features of over-abundant application, low utilization rate, and large loss. There are few clay layers in the aquifer, and the depth to groundwater is shallow, the aquifer was in a relatively oxidizing environment and the amounts of nitrite and ammonium are generally lower in the aquifer; therefore, nitrogen is a major pollutant with high concentrations and a wide distribution from domestic, industrial, and agricultural pollution.

To ascertain the groundwater quality of the plain, 877 shallow groundwater samples were collected from June 2012 to September 2014 - mainly in May to September (Fig. 1). Water sampling used the principle of average distribution, and sampling density is $1 \mathrm{Group} / 100 \mathrm{~km}$.

\section{Intrinsic Vulnerability}

Intrinsic vulnerability assessment is an effective tool for describing innate features of specific hydrogeological conditions that provide some measure of defense against external contamination. Intrinsic vulnerability is independent of the nature of the specific contaminants and the contamination scenario and takes into account the geological, hydrological, and hydrogeological characteristics of an area [37]. The most popular tool for assessing intrinsic groundwater vulnerability is the DRASTIC model [18], which is based on the following seven morphological, hydrological, and hydrogeological parameters: depth to groundwater (D), net recharge (R), aquifer media (A), soil media (S), topography (T), impact of the vadose zone (I), and hydraulic conductivity (C). Each parameter is divided into classes with a rating value and has a weight based on their importance. The groundwater vulnerability assessment using the DRASTIC model is based on a numerical ranking that considers weights, ranges, and ratings. For each of the seven factors, ratings from 1 to 10 and weights from 1 to
5 are attributed by the contribution of each parameter in the groundwater vulnerability. The DRASTIC index (DI) [2] is calculated by applying a linear combination of all the factors according to Eq. (1):

$$
\begin{gathered}
D I=D r * D w+R r * R w+A r * A w+S r \\
* S w+T r * T w+I r * I w+C r * C w
\end{gathered}
$$

...where D, R, A, S, T, I, and C are as defined earlier; $r$ is the rating for the study area; and $\mathrm{w}$ is the weight of each parameter. The raw data that were collected or derived from various published reports, drill-holes, and hydro meteorology are listed in Table 1.

Intrinsic groundwater vulnerability mapping can be graded into several classifications: low, relatively low, moderate, relatively high, and high vulnerability to potential pollution. The higher the DIs, the greater the intrinsic groundwater vulnerability.

\section{Specific Vulnerability}

In recent years, specific vulnerability has been widely used for groundwater vulnerability - especially for the impact of human factors. In the improvements of the DRASTIC model proposed by several researchers, factors were subtracted from the model [38] or factors like land use or irrigation type and groundwater quality were added to the model [39]. DRASTIC has been incorporated into other procedures or models, such as DRASIC and DRATIL $[24,30]$. In this paper, to take into account the influence of human factors on groundwater vulnerability in the West Liaohe Plain, groundwater use (quality and quantity), land use type, and model of groundwater resource yield are added to the DRASTIC model of specific vulnerability. Land use types are not contaminant indicators in the specific groundwater vulnerability assessment, but are major factors affecting the fate and

Table 1. Data sources for the seven parameter data layers.

\begin{tabular}{|c|c|c|}
\hline Parameters & Data sources & $\begin{array}{c}\text { Scale of map } \\
\text { prepared }\end{array}$ \\
\hline $\mathrm{D}$ & $\begin{array}{c}1134 \text { monitoring wells, } \\
\text { 2012-14 }\end{array}$ & $1: 250,000$ \\
\hline $\mathrm{R}$ & $\begin{array}{c}\text { precipitation and irrigation } \\
\text { data from 2012-14 }\end{array}$ & $1: 250,000$ \\
\hline $\mathrm{A}$ & $\begin{array}{c}766 \text { hydrogeological drill-hole } \\
\text { data, 2007-09 }\end{array}$ & $1: 250,000$ \\
\hline $\mathrm{S}$ & $\begin{array}{c}\text { 828 particle size analysis of } \\
\text { soil samples, 2012-14 }\end{array}$ & $1: 250,000$ \\
\hline $\mathrm{T}$ & $\begin{array}{c}766 \text { hydrogeological drill-hole } \\
\text { data, 2007-09 }\end{array}$ & $1: 250,000$ \\
\hline $\mathrm{I}$ & $\begin{array}{c}766 \text { hydrogeological drill-hole } \\
\text { data, 2007-09 }\end{array}$ & $1: 250,000$ \\
\hline $\mathrm{C}$ & $\begin{array}{c}766 \text { hydrogeological drill-hole } \\
\text { data, 2007-09 }\end{array}$ & $1: 250,000$ \\
\hline
\end{tabular}


transformation of contaminants such as nitrates in the vadose zone and the aquifer; the behavior of pollutants in the vadose zone and the aquifer may differ according to the different types of land use. Models of groundwater resource yield are not an indicator of groundwater contamination and vulnerability, but are important factors determining the amount of exploitation. Usually, intensive human activities and groundwater exploitation not only generate more pollutants, but also increase the recharge amounts, and therefore the possibility that contaminants will reach the aquifer is greater. Thus, land use type and models of groundwater resource yield should be considered as groundwater vulnerability parameters to make the specific vulnerability result more meaningful.

In some cases, a correlation between the results of the model and actual pollution occurrence were used to validate and verify the model's performance. Nitrate was widely used to check the models for that purpose. Therefore, the methodology developed in this paper for the evaluation of specific vulnerability uses nitrate concentration to match each parameter, and then modifies them with various transformations and additions to improve specific vulnerability. The effective criterion for these transformations is the correlation coefficient between the parameter value and nitrate concentration at a point. Other researchers have verified the correlation between intrinsic vulnerability and actual pollution occurrence defined by nitrate concentrations [29-30].

The calculation process and meanings of each index of specific vulnerability models are the same as in the above DRASTIC model, but the ratings and weights were modified by the correlation coefficient, and the groundwater vulnerability was recalculated.

\section{Statistical Methods}

\section{Correlation Factor}

The correlation between nitrate concentrations and groundwater vulnerability has been used as an indicator of the reliability and accuracy of the applied methods [29-32]. The reliability of the correlation is based on the groundwater samples (a point measurement) according to the specific characteristics of the area, such as aquifer media, land use type, and net recharge.

The correlation can be calculated by Pearson's $r$ correlation coefficient and Spearman's rank correlation factor $(\rho)$. Pearson's correlation has been used to validate the weighting, rating, and parameter class range of the groundwater vulnerability with two variables and a large sample size [40]. Pearson's $r$ was used to modify the weights and ratings of the parameters, and determine the grading method of the groundwater vulnerability. Therefore, Pearson's $r$ correlation method can be applied as follows:

$$
r_{X, Y}=\frac{\sum_{i=1}^{N}\left(X_{i}-\bar{X}\right)\left(Y_{i}-\bar{Y}\right)}{\sqrt{\sum_{i=1}^{N}\left(X_{i}-\bar{X}\right)^{2} \sum_{i=1}^{N}\left(Y_{i}-\bar{Y}\right)^{2}}}
$$

...where $r_{X Y}$ is the correlation coefficient, $N$ is the sample size, $X$ is the nitrate concentration, and $Y$ is the rating of the parameter, such as land use, aquifer type, and depth of groundwater. The greater $r_{X, Y}$, the stronger the correlation.

\section{ANOVA F-statistic}

Analysis of F-statistics, which are the ratios of the variability between groups compared with the variability within groups based on the significance test of regression coefficients to judge the fitting degree of multivariate linear regression [41], was used to verify the overlap between nitrate concentrations and groundwater vulnerability classes. The larger the ANOVA F-statistic, the less the overlap between the nitrate concentrations in the different vulnerability classes [40]. The variance (ANOVA) F-statistic can be calculated by Eq. (3).

$$
F=\frac{M S T}{M S E}=\frac{S S T / k-1}{S S E / n-k}
$$

...where MST is the mean square and MSE is the mean square error. $S S T$ and $S S E$ are the sum of squares for treatment and the sum of squares for error, respectively, and $k-1$ and $n-k$ are the freedom degree for treatment and freedom degree for error, respectively.

\section{Sensitivity Analysis}

A high number of input data layers were used in the DRASTIC model. This was regarded as a major advantage; the larger the number of data layers, the smaller the impact of errors or uncertainties of the individual parameters on the final output [37-38]. Sensitivity analysis provides information on the influence of the ratings and the weights assigned to each of the factors considered in the model to judge the significance of the subjective elements. Two sensitivity analysis tests can be performed: the map removal sensitivity analysis introduced by Lodwick et al. [42], and the single-parameter sensitivity analysis introduced by Napolitano and Fabbri [43]. In this study, the single-parameter sensitivity analysis was chosen to evaluate the impact of each DRASTIC parameter on the vulnerability index by comparing their effective weights with their theoretical weights [44]. The effective weight of each parameter is calculated as follows:

$$
W=\left(P_{r} * P_{w} / D I\right) * 100
$$

...where $W$ is the effective weight of each parameter, $P_{r}$ and $P_{w}$ are the rating value and weight of each parameter, respectively, and $D I$ is the overall vulnerability index. 


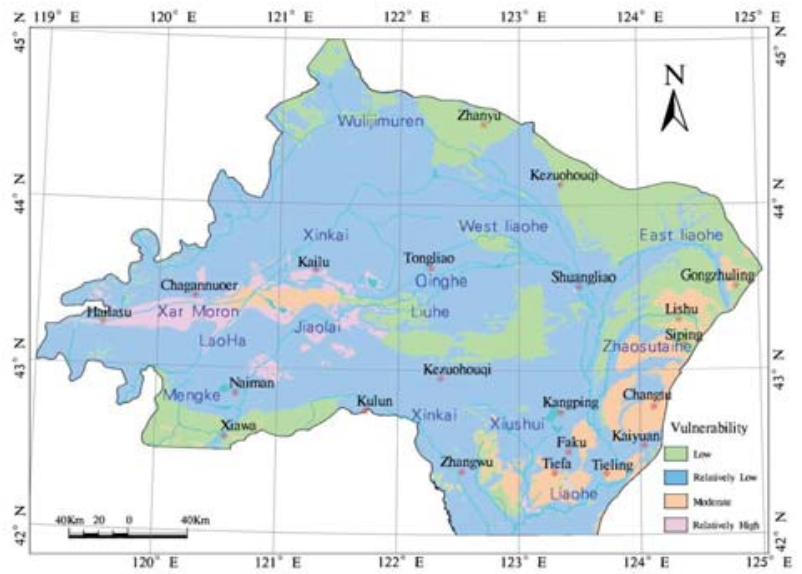

Fig. 3. Map of intrinsic vulnerability based on DRASTIC.

\section{Results and Discussion}

\section{Applying the DRASTIC Model to Intrinsic Vulnerability}

An intrinsic vulnerability map of the West Liaohe Plain was created using DRASTIC. Data sources are shown in Table 1. The weights, ratings, and values of vulnerability indexes have been complied with the values given by Aller et al. [2]. The vulnerability index was calculated on the platform of ArcGIS.

The intrinsic vulnerability index (DI) in the West Liaohe Plain was 57-173 and was divided into four classes: low, relatively low, moderate, and relatively high (Fig. 3). The western parts of the plain have a relatively high vulnerability class, meaning they are more easily polluted than the other areas by external contamination; the main reasons for this are the shallow groundwater table, high hydraulic conductivity, or the sand and gravel media in the aquifer and vadose zone. In the central and southeastern area of the plain, the vulnerability class is moderate because of either the moderately shallow groundwater table or high hydraulic conductivity and vadose zone. The relatively low areas are widely distributed in the plain as a result of a deep groundwater table or the hydrogeological characteristics of the shale and sandstone media of the aquifer, and of the vadose zone (mainly sandy loam or loam). The low-vulnerability areas are somewhat scattered; in the central, northern, and northeastern areas of the plain, the low classification is caused by the slower velocity of groundwater movement, the relatively closed environment, and increased depth.

\section{Validating the Relationship between Intrinsic Vulnerability and Nitrate}

The correlation between the vulnerability index and point nitrate concentration values was used to validate the relationship between intrinsic vulnerability and actual pollution. The map of $\mathrm{NO}_{3}-\mathrm{N}$ concentrations for shallow groundwater (Fig. 4) was based on 877 shallow

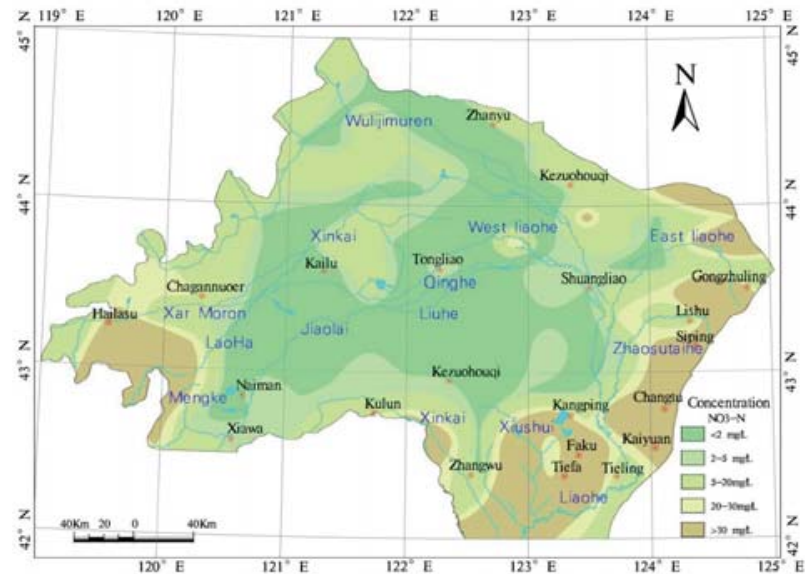

Fig. 4. Concentrations of $\mathrm{NO}_{3}-\mathrm{N}$ in shallow groundwater.

groundwater samples collected from 2012 to 2014 mainly in May to September. Fig. 4 shows that the concentrations of $\mathrm{NO}_{3}-\mathrm{N}$ were divided into five categories according to the quality standards for groundwater in China (www.standarden.com). $\mathrm{NO}_{3}-\mathrm{N}$ in the study area is mainly from domestic, industrial, and agricultural pollution. Higher nitrate concentrations were found in the east, west, and south of the study area, and the intensity of human activities in the regions were larger than others with larger urban populations, more industrial activities, and agricultural production; lower concentrations were found in the north and middle of the study areas, because the main types of land use are grassland, woodland, and wasteland, while urban areas and farmland are small, the concentration of $\mathrm{NO}_{3}-\mathrm{N}$ was lower. The proportions of each of the five categories of the total, from low to high, were $33.07 \%, 16.13 \%, 28.24 \%, 7.39 \%$, and $15.16 \%$. The maximum, minimum, and average concentrations of $\mathrm{NO}_{3}-\mathrm{N}$ were $117.32 \mathrm{mg} / \mathrm{L}, 0.004 \mathrm{mg} / \mathrm{L}$, and $11.76 \mathrm{mg} / \mathrm{L}$, respectively, and the median is $0.79 \mathrm{mg} / \mathrm{L}$.

Pearson's $r$ correlation between the vulnerability index and nitrate concentration values was only 0.243 , which was a very low correlation. By comparing Figs 3 and 4 , it can be seen that higher intrinsic vulnerability sometimes corresponds to lower $\mathrm{NO}_{3}-\mathrm{N}$ concentrations and sometimes the opposite. The conclusion from these comparisons and observations is that the DRASTIC results do not reflect actual groundwater vulnerability, and the model needs to be improved if it is to be used to research actual groundwater pollution. Using previous research, and the characteristics of the study area, a methodology was developed to incorporate nitrate into groundwater vulnerability by retaining the basic structure of the DRASTIC model and optimizing it with various transformations and additions. The optimization of the methodology assumed: 1) the index system needs to be rebuilt by adding or subtracting parameters, 2) the rating scale of each parameter needs to be revised, 3) the weights of the parameters need to be revised, and 4) the most appropriate method must be determined and selected. 


\section{Optimizing the DRASTIC Model for Specific Vulnerability to Nitrate}

\section{Rebuilding the Index System by Adding Parameters}

The effect of human activities on groundwater vulnerability is mainly manifested in its quality and quantity aspects, such as pollution and over-exploitation. Based on the above study of specific vulnerability in the West Liaohe Plain, land use type and models of groundwater resource yield can be considered groundwater vulnerability parameters. The index system of the new model to evaluate groundwater vulnerability to nitrate pollution comprises depth to groundwater (D), net recharge (R), aquifer media (A), soil media (S), topography (T), impact of the vadose zone (I), hydraulic conductivity (C), land use type (L), and model of groundwater resource yield (M). Therefore, the new model was named DRASTIC-LM. The rating scales of $\mathrm{D}, \mathrm{R}, \mathrm{A}, \mathrm{S}, \mathrm{T}, \mathrm{I}$, and $\mathrm{C}$ were the same as those in the original DRASTIC model [2]. Land use type and the groundwater resource yield model have different effects on groundwater vulnerability in different study areas, and specific vulnerability assessment needs-dedicated rating scales. The rating scales for land use type and model of groundwater resource yield (Table 2) were based on the results of Huan et al. [7], Li and Merchant [45], and Panagopoulos et al. [30]. The weights used for D, R, A, S, T, I, C were 5, 4, 3, 2, 1, 5, and 3. Because of the importance of land use type and model of groundwater resource yield in reflecting human activities, their weights were set to 5 and 4, respectively. The greater the intensity of human activity, the higher the rating scales and weights.

Specific vulnerability to nitrate was assessed by the rebuilt DRASTIC-LM model. Fig. 5 shows that the area of relatively high vulnerability class is larger than that in the intrinsic vulnerability assessment; it occurs mainly in the southeast of the study area, where the concentration of $\mathrm{NO}_{3}-\mathrm{N}$ is also higher. The distribution rule in the other regions did not fit the concentration of $\mathrm{NO}_{3}-\mathrm{N}$ well. Pearson's correlation factor between the

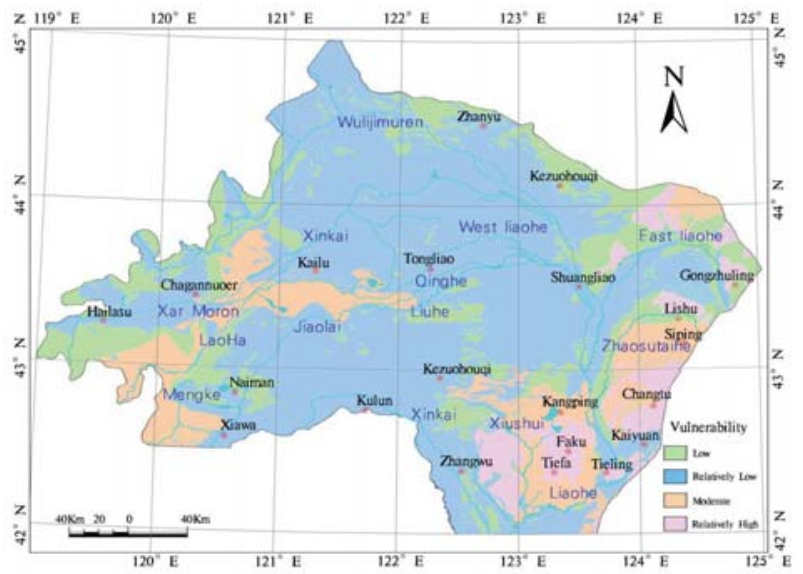

Fig. 5. Map of specific vulnerability based on DRASTIC-LM.
Table 2. Rating scales for land use types and model of groundwater resource yield.

\begin{tabular}{|c|c|c|c|}
\hline \multicolumn{2}{|c|}{ Land use type } & \multicolumn{2}{c|}{$\begin{array}{c}\text { Model of groundwater } \\
\text { resource yield }\end{array}$} \\
\hline Types & Value & $\begin{array}{c}\text { Range } \\
\left(\mathrm{m}^{3} / \mathrm{akm}^{2}\right)\end{array}$ & Value \\
\hline Forest, grassland & 2 & $<3$ & 1 \\
\hline Paddy field & 4 & $3-5$ & 3 \\
\hline $\begin{array}{c}\text { Surface water, } \\
\text { upland field }\end{array}$ & 6 & $5-10$ & 5 \\
\hline Urban fabric & 8 & $10-20$ & 7 \\
\hline Industrial land & 10 & $20-30$ & 9 \\
\hline
\end{tabular}

vulnerability index and the concentration of $\mathrm{NO}_{3}-\mathrm{N}$ increased to 0.386 , which was larger than that obtained by the initial DRASTIC model, but still small. To improve the reliability of the specific vulnerability assessment by the rebuilt DRASTIC-LM model, the rating scale of each parameter needs to be revised based on their relationship with concentrations of $\mathrm{NO}_{3}-\mathrm{N}$.

\section{Revising the Rating Scale of Each Parameter}

The most effective way to improve the accuracy of results of the specific vulnerability evaluation is to increase the rationality of the rating scale. Revising the rating scales can be accomplished by simple statistical methods to link the mean class of each parameter defined in the DRASTIC-LM model to the concentration of $\mathrm{NO}_{3}-\mathrm{N}$.

Classes of each parameter were grouped for these cases, while for noncontinuous parameters (parameters with discrete classes), such as aquifer media, vadose zone type, soil type, and land use type, all the categories existing in the area were maintained regardless of statistical diversity. The original and modified rating values of the DRASTIC-LM parameters and the average

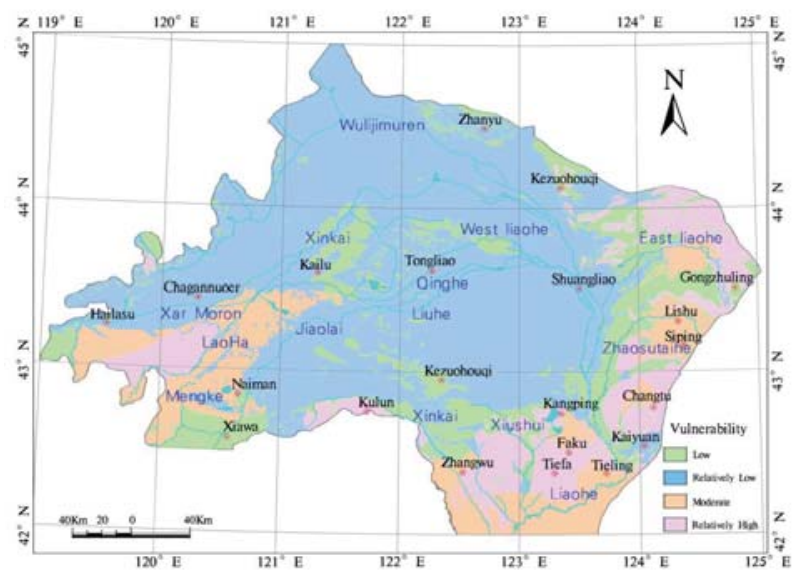

Fig. 6. Map of specific vulnerability based on modified DRASTIC-LM (optimized by revising the rating scale). 
Table 3. Original and modified rating values of the DRASTIC-LM parameters.

\begin{tabular}{|c|c|c|c|c|c|c|c|c|c|c|c|}
\hline \multicolumn{4}{|c|}{ Depth to groundwater } & \multicolumn{4}{|c|}{ Net recharge } & \multicolumn{4}{|c|}{ Aquifer media } \\
\hline Range (m) & A & $\mathrm{B}$ & $\mathrm{C}$ & Range (mm) & A & B & $\mathrm{C}$ & Aquifer media & A & B & $\mathrm{C}$ \\
\hline $9-15$ & 5 & 17.76 & 1.85 & $<51$ & 1 & 33.07 & 2.73 & Metamorphic rocks & 3 & 17.96 & 2.72 \\
\hline $4.5-7$ & 8 & 40.31 & 4.20 & $51-71$ & 2 & 52.368 & 4.33 & Conglomerate & 4 & 25.74 & 3.89 \\
\hline $1.5-4.5$ & 9 & 79.9 & 8.33 & $71-91$ & 3 & 46.2 & 3.82 & Block sandstone & 6 & 46.91 & 7.09 \\
\hline \multirow[t]{3}{*}{$<1.5$} & 10 & 95.87 & 10.00 & $91-117$ & 4 & 60.53 & 5.00 & Sand & 7 & 49.34 & 7.46 \\
\hline & & & & & & & & Sand gravel & 8 & 44.9 & 6.79 \\
\hline & & & & & & & & Limestone & 9 & 66.13 & 10.00 \\
\hline \multicolumn{4}{|c|}{ Soil type } & \multicolumn{4}{|c|}{ Topography } & \multicolumn{4}{|c|}{ Impact of the vadose zone } \\
\hline Soil type & A & B & $\mathrm{C}$ & $\begin{array}{c}\text { Range slope } \\
(\%)\end{array}$ & A & B & $\mathrm{C}$ & Geological formation & A & B & $\mathrm{C}$ \\
\hline Clay loam & 3 & 17.72 & 1.73 & $>18$ & 1 & 30.73 & 2.75 & Loam & 2 & 41.25 & 3.27 \\
\hline Sandy clay & 4 & 28.13 & 2.74 & $12-18$ & 3 & 36.97 & 3.30 & Shale & 3 & 37.83 & 3.00 \\
\hline Loam & 5 & 29.46 & 2.87 & $6-12$ & 5 & 55.84 & 4.99 & Sandstone & 5 & 52.88 & 4.19 \\
\hline Sandy Loam & 6 & 41.7 & 4.07 & $2-6$ & 9 & 79.92 & 7.14 & Limestone & 6 & 56.15 & 4.45 \\
\hline Sand & 9 & 78.51 & 7.66 & $0-2$ & 10 & 111.92 & 10.00 & Igneous rock & 7 & 69.97 & 5.55 \\
\hline \multirow[t]{2}{*}{ Gravel } & 10 & 102.56 & 10.00 & & & & & Gritstone & 8 & 91.25 & 7.23 \\
\hline & & & & & & & & Conglomerate & 9 & 126.15 & 10.00 \\
\hline \multicolumn{4}{|c|}{ Hydraulic conductivity } & \multicolumn{4}{|c|}{ Land use type } & \multicolumn{4}{|c|}{ Model of groundwater resource yield } \\
\hline Range (m/d) & A & B & $\mathrm{C}$ & Type & A & B & $\mathrm{C}$ & $\begin{array}{c}\text { Range } \\
\left(\mathrm{m}^{3} / \mathrm{a}^{2} \mathrm{~km}^{2}\right)\end{array}$ & A & B & $\mathrm{C}$ \\
\hline $4.1-12.2$ & 2 & 38.01 & 3.53 & $\begin{array}{l}\text { Forest, } \\
\text { grassland }\end{array}$ & 2 & 36.7 & 3.22 & $<3$ & 2 & 42.68 & 3.41 \\
\hline $12.2-20.3$ & 3 & 54.97 & 5.11 & paddy field & 4 & 33.84 & 2.97 & $3-5$ & 3 & 56.69 & 4.53 \\
\hline $20.3-28.5$ & 4 & 49.67 & 4.61 & $\begin{array}{c}\text { Surface } \\
\text { water,upland } \\
\text { field }\end{array}$ & 5 & 65.33 & 5.73 & $5-10$ & 5 & 67.66 & 5.41 \\
\hline \multirow[t]{2}{*}{$28.5-34.6$} & 5 & 75.36 & 7.00 & Urban fabric & 8 & 98.95 & 8.68 & $10-20$ & 7 & 114.02 & 9.11 \\
\hline & & & & $\begin{array}{l}\text { Industrial } \\
\text { land }\end{array}$ & 10 & 114 & 10.00 & $20-30$ & 9 & 125.18 & 10.00 \\
\hline
\end{tabular}

A: Original rating; B: Mean concentration of $\mathrm{NO}_{3}-\mathrm{N}(\mathrm{mg} / \mathrm{L})$; C: Modified rating value.

nitrate concentrations are shown in Table 3. Modified rating values were derived using the mean nitrate concentrations of each class reduced to a 10 -grade scale. Because the original rating values of net recharge (4) and hydraulic conductivity (5) were smaller than those of other parameters (9 and 10), the modified rating values have been revised appropriately to 5 and 7 . Although the modified rating is not on a 10 -grade scale, the result is more reasonable and reliable [45].

From Table 3 we can see that in all the continuous parameters (depth to groundwater, net recharge, topography, hydraulic conductivity, and modeled groundwater resource yield), the mean nitrate concentrations follow the same ascending or descending trend as the respective natural range values, and the relative factor rates for each class. Following the revision of the rating scales, the applied modified DRASTIC-LM model increases its correlation with the nitrate concentrations to $r=0.513$ (Fig. 6). The $r$ value is 0.127 greater than the original DRASTIC-LM model, but the improvement in correlation is not obvious from Fig. 5 to Fig. 6; in some zones there is no agreement with concentrations. The vulnerability in some grassland and forest areas was moderate, while the vulnerability in some urban and industrial areas was relatively low. To improve the correlation further, a revision of the parameter weights might be needed.

\section{Revising the Parameter Weights}

The weights of the parameters represent their relative importance in the model: the higher the weight, the greater 
Table 4. Correlation coefficient values and revised weights.

\begin{tabular}{|c|c|c|c|}
\hline Parameter & $\begin{array}{c}\text { Original } \\
\text { weights }\end{array}$ & $\begin{array}{c}\text { Pearson's } \\
(r) \\
\text { correlation }\end{array}$ & $\begin{array}{c}\text { Revised } \\
\text { weights }\end{array}$ \\
\hline Depth to groundwater & 5 & 0.452 & 5 \\
\hline Net recharge & 4 & 0.291 & 3 \\
\hline Aquifer media & 3 & 0.394 & 4 \\
\hline Soil type & 2 & 0.135 & 1 \\
\hline Topography & 1 & 0.103 & 1 \\
\hline $\begin{array}{c}\text { Impact of the vadose } \\
\text { zone }\end{array}$ & 5 & 0.421 & 4 \\
\hline Hydraulic conductivity & 3 & 0.342 & 3 \\
\hline Land use type & 5 & 0.496 & 5 \\
\hline $\begin{array}{c}\text { Model of groundwater } \\
\text { resource yield }\end{array}$ & 4 & 0.483 & 5 \\
\hline
\end{tabular}

its importance. The weights of the parameters in different areas may have a different influence on groundwater vulnerability. For example, aquifer media and the vadose zone, which significantly affect the concentration of $\mathrm{NO}_{3}-\mathrm{N}$, were assigned low and high weights, respectively. However, it is not clear whether this would always apply to the study area. The weights for the study area need to be determined.

The weights of the model in the earlier sections of this paper were obtained from previous research; the next step in the DRASTIC-LM model modification is to revise the weights for each parameter. This revision is accomplished by calculating the correlation between each parameter and the mean concentration of $\mathrm{NO}_{3}-\mathrm{N}$. The correlation was calculated using Pearson's $r$. Based on these coefficients, and after their values were reduced to a scale with a maximum value of 5 , as defined by the model, the new weighting factors were calculated. In cases where a coefficient was statistically significant, the corresponding parameter was excluded from the vulnerability equation.

Table 4 shows the Pearson's $r$ values and the revised weighting factors; it is clear that the "topography" and "soil type" parameters are not statistically significant and should be excluded. The insignificant correlation between "soil type" and "concentration of $\mathrm{NO}_{3}-\mathrm{N}$ " reveals that the soil type does not influence the nitrate concentrations in the groundwater. The same conclusion was reached by McLay et al. [29] and Lambrakis et al. [46]. The insignificant correlation between "topography" and "concentration of $\mathrm{NO}_{3}-\mathrm{N}$ " means that small differences in topography do not influence nitrate concentrations. This conclusion is consistent with the findings of Stigter et al. [47] and Huan et al. [7]. It can also be seen that depth to groundwater, hydraulic conductivity, and land use type were not changed. However, net recharge and impact of the vadose zone decreased, although they remained relatively high. In addition, aquifer media and modeled groundwater resource yield were increased; their changed weight reflects their increased importance in the evaluation process. The revised weights for depth to groundwater, net recharge, aquifer media, hydraulic conductivity, impact of the vadose zone, land use type, and modeled groundwater resource yield were 5, 3, 4, 3, 4,5 , and 5 , respectively. The new assessment model was abbreviated to DRACILM.

After the application of the revised weighting indexes and removal of the two non-correlated parameters, the DRACILM index (DRI) can be calculated by Eq. (5) as follows:

$$
\begin{gathered}
D R I=D * 5+R * 3+A * 4+C * \\
3+I * 4+L * 5+M * 5
\end{gathered}
$$

...where $D R I$ is the specific vulnerability index to nitrate. With the application of the above equation, the correlation between groundwater vulnerability index and the concentration of $\mathrm{NO}_{3}-\mathrm{N}$ is further increased, and Pearson's $r$ is now 0.649. Fig. 7 shows the results of DRI divided into four classes: low, relatively low, moderate, and relatively high. The western, eastern, and southeastern parts of the plain have a relatively high vulnerability class as a result of them being more easily polluted because of the shallow groundwater table, higher hydraulic conductivity, or increased intensity of human activity (industrial and urban land use, modeled groundwater resource yield is higher). In isolated areas in the western, eastern, and southeastern parts of the plain, the vulnerability class is moderate: a result of the decreased intensity of human activity compared with the relatively high-vulnerability parts. The "relatively low" areas are the most widely distributed in the plain; they are caused by the deep groundwater table, grassland and paddy field land use, and a small resource yield from the groundwater model. The scattered low-vulnerability areas are mostly found in the northern and central parts; the low classification is a result of the smallest intensity of human activity, relatively closed environment, and

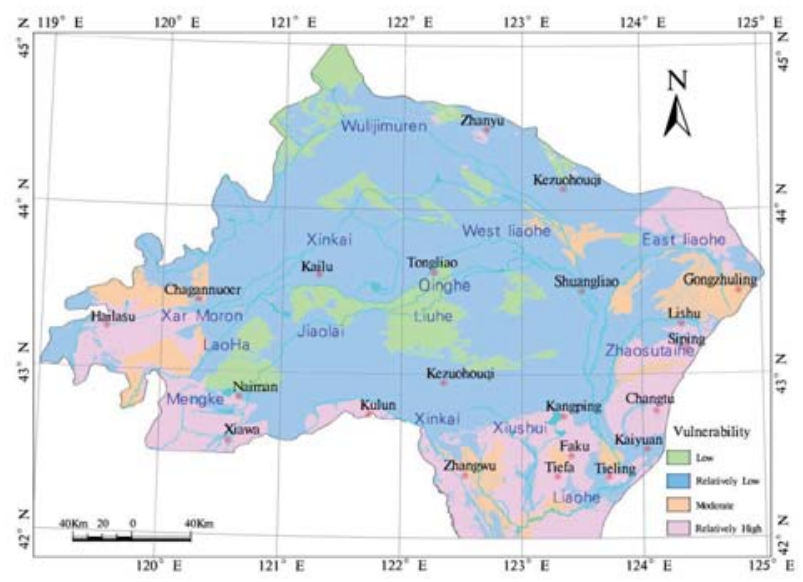

Fig. 7. Map of specific vulnerability based on the modified DRACILM model. 
Table 5. Correlation coefficients of the various models.

\begin{tabular}{|c|c|c|c|c|}
\hline Model & $\begin{array}{c}\text { Pearson's }(r) \\
\text { correlation factor }\end{array}$ & $\begin{array}{c}\text { Step correlation } \\
\text { improvement (\%) }\end{array}$ & $\begin{array}{c}\text { Overall correlation } \\
\text { improvement (\%) }\end{array}$ & $\begin{array}{c}\text { ANOVAF } \\
\text { Statistic }\end{array}$ \\
\hline DRASTIC model & 0.243 & - & - & 12.94 \\
\hline DRASTIC-LM model & 0.386 & 14.3 & 14.3 & 15.22 \\
\hline Optimized DRASTIC-LM model & 0.513 & 12.7 & 27 & 23.68 \\
\hline DRACILM model & 0.649 & 13.6 & 40.6 & 27.71 \\
\hline
\end{tabular}

a deeper water table. Excluding the non-correlated natural factors and improving the integration of human activity made the result more reasonable and reliable. The DRACILM model is therefore appropriate for assessing the groundwater-specific vulnerability in the West Liaohe Plain.

\section{Selection of the Most Appropriate Model for Specific Vulnerability to Nitrate}

To identify the most appropriate model for groundwater vulnerability to nitrate pollution in the plain, several methods were introduced in previous research, such as the correlation between groundwater vulnerability classes and the concentration of $\mathrm{NO}_{3}-\mathrm{N}$, and analysis of F-statistic variances. Table 5 summarizes the intrinsic vulnerability and specific vulnerability correlation coefficients resulting from the modification and optimization of the DRASTIC method using $\mathrm{NO}_{3}-\mathrm{N}$ data in models such as DRASTIC, DRASTIC-LM, optimized DRASTICLM, and DRACILM. A progressive improvement in the precision of the intrinsic and specific vulnerability is accomplished, as expressed by Pearson's $r$. From Table 5 it can be observed that Pearson's $r$ between the groundwater vulnerability index calculated by the DRACILM model and the concentration of $\mathrm{NO}_{3}-\mathrm{N}$ increased to 0.649 , which is $40.6 \%$ larger than that obtained by DRASTIC. The substantial increase in Pearson's $r$ might be the result of several key steps. First, the correlation between DRASTIC-LM and nitrate concentrations improved by up to $14.3 \%$ compared with the original DRASTIC model, by adding the effect of human activities to the assessment of groundwater vulnerability model. Human activity was determined from land use type and modeled groundwater resource yield. Second, the correlation between nitrate concentrations and optimized DRASTIC-LM increased by $27 \%$ compared with the original DRASTIC model. This was accomplished by revising the rating scales of each parameter based on statistical evaluations of nitrate concentrations. Third, a further improvement of $40.6 \%$ was achieved by excluding the parameters that had low correlations with nitrate concentrations (i.e., soil, media, and topography). The modification of the rating scales and the removal of these parameters may be beneficial for groundwater vulnerability assessments for the specific study area. The resulting ANOVA F-statistic was greater than 27.71 when the modified models were compared with the original DRASTIC methods, as a result of the lower overlap between the mean values of nitrates in the different vulnerability classes. The higher the ANOVA F-statistic for an assessment method, the higher the Pearson's $r$. Based on these criteria, DRACILM is the most appropriate model for assessing specific vulnerability to nitrate in the study area. By comparing Figs 2 and 4, we can see that the rule linking $\mathrm{NO}_{3}-\mathrm{N}$ and the groundwater vulnerability index is consistent. The concentrations of nitrate were divided into five levels, with level 5 being the highest. Nitrate concentration levels 5 and 4 correspond to relatively high and moderate vulnerability classes, respectively; although the intensity of human activities is higher in these areas, natural attenuation of pollution is slightly improved. Nitrate concentration levels 3 and

Table 6. Statistics of the single-parameter sensitivity analysis.

\begin{tabular}{|c|c|c|c|c|c|c|}
\hline \multirow{2}{*}{ Parameter } & \multirow{2}{*}{$\begin{array}{c}\text { Theoretical } \\
\text { weight }\end{array}$} & \multirow{2}{*}{$\begin{array}{l}\text { Theoretical } \\
\text { weight (\%) }\end{array}$} & \multicolumn{4}{|c|}{ Effective weighting (\%) } \\
\hline & & & Min & Max & Average & Standard deviation \\
\hline Depth to groundwater & 5 & 17.24 & 4.21 & 46.16 & 17.69 & 2.14 \\
\hline Net recharge & 3 & 10.34 & 0.76 & 31.47 & 7.16 & 8.67 \\
\hline Aquifer media & 4 & 13.79 & 2.53 & 42.01 & 15.22 & 5.52 \\
\hline Impact of the vadose zone & 4 & 13.79 & 2.72 & 40.65 & 10.05 & 9.43 \\
\hline Hydraulic conductivity & 3 & 10.34 & 1.11 & 39.27 & 8.76 & 7.17 \\
\hline Land use type & 5 & 17.24 & 5.43 & 58.66 & 22.41 & 3.28 \\
\hline Model of groundwater resource yield & 5 & 17.24 & 3.89 & 47.19 & 18.70 & 4.31 \\
\hline
\end{tabular}


2 correspond to the relatively low-vulnerability class, and level 1 corresponds to the low-vulnerability class; in these areas the intensity of human activity is not high, but natural protection against pollution is low. Therefore, the specific vulnerability class approached the real vulnerability conditions and is thus more reasonable and reliable. DRACILM is the most appropriate model for assessing specific vulnerability to nitrate pollution in the West Liaohe Plain, and thus the model could be used for groundwater protection and management.

\section{Sensitivity Analysis of the Modified DRACILM Model}

A single-parameter sensitivity analysis allows a comparison between effective and theoretical weights (Table 6). The effective weight of the DRACILM parameters is a function of their theoretical weight and their interaction with the six other parameters in DRACILM. The effective weight of the DRACILM parameters obtained in this study exhibited some deviation from the theoretical weights.

Based on the statistics of the single-parameter sensitivity analysis (Table 6), the effective weighting is between $7.16 \%$ and $22.41 \%$, indicating that the seven indexes in the vulnerability assessment do not differ greatly. The effective weights for L, M, D, and A $(22.41 \%$, $18.70 \%, 17.69 \%$, and $15.22 \%$, respectively) are higher than their theoretical weights $(17.24 \%, 17.24 \%, 17.24 \%$, and $13.79 \%$, respectively). The parameters of land use type and modeled groundwater resource yield tend to be the two most effective parameters in the specific vulnerability assessment; the statistical results are in agreement with the observation that the effect of human activities is the main influence in the vulnerability assessment. The mean effective values of $22.41 \%$ and $18.70 \%$ are higher than others. The effective weights of the I, C, and R parameters $(10.05 \%, 8.76 \%$, and $7.16 \%$, respectively) are less than their theoretical weights $(13.79 \%, 10.34 \%$, and $10.34 \%$, respectively, which have standard deviations of $9.43 \%$, $7.17 \%$, and $8.67 \%$, respectively). The net recharge and hydraulic conductivity have an insignificant impact on the groundwater vulnerability compared with the other six parameters. The value of each effective weighting is in accordance with the correlation between concentrations of nitrate and the seven parameters, as shown by Pearson's $r$ (Table 4); land use type exhibited the highest value and hydraulic conductivity the lowest.

\section{Utilities of Vulnerability Maps for Groundwater Protection and Management}

The protection and management of groundwater resources promote their sustainable use and availability for future generations. Assessing groundwater vulnerability is essential for protecting and managing groundwater resources and the environment in the West Liaohe Plain. Groundwater vulnerability maps can be used to help formulate the strategies by government and planners to prevent groundwater resource pollution by industry, agriculture, and households. In general, the specific vulnerability assessment maps calculated using DRACILM can be considered a combination of intrinsic vulnerability assessment and the effect of human activities into a simple map. The resulting vulnerability maps could assist planners and government decision-makers in planning water protection projects or establishing management scenarios for water resource quality. Emphasis should be placed on relatively highvulnerability areas where self-protection of the aquifer is not sufficient to protect water quality. Specific measures were taken by the central government in its $13^{\text {th }}$ Five Year Plan to prevent selective activities polluting groundwater resources in highly vulnerable areas. DRACILM is the most appropriate model for assessing specific vulnerability to nitrate pollution for groundwater protection and management in the West Liaohe Plain.

\section{Conclusions}

The DRASTIC method can provide satisfactory results for intrinsic vulnerability assessments. However, it is not the best method for accurately assessing specific vulnerability in the study area. The study area has high nitrate concentrations as a result of human activities. To address this issue, a method was developed that retained the basic structure of DRASTIC, but 1) added parameters (land use type, model of groundwater resource yield), 2) subtracted parameters (topography, soil type), and 3) modified the parameter ratings and weightings by applying data on $\mathrm{NO}_{3}-\mathrm{N}$ concentrations to the seven statistical parameters in an optimization procedure. The DRACILM model was developed to assess groundwater vulnerability to nitrate pollution in the West Liaohe Plain and create vulnerability maps.

The correlation between vulnerability class and the concentration of $\mathrm{NO}_{3}-\mathrm{N}$ in the DRACILM model improved to 0.649 , which is $40.6 \%$ higher than that obtained using the DRASTIC model. The ANOVA F-statistic increased to 27.71, which indicated the lower overlap between the mean values of nitrates in the different vulnerability classes. A single-parameter sensitivity analysis revealed that the effective weighting is between $7.16 \%$ and $22.41 \%$, indicating that the seven indexes in the vulnerability assessment do not differ greatly. The value for each effective weighting accords with the correlations between nitrate concentrations and the seven parameters; land use type had the highest weighting value and hydraulic conductivity the lowest.

The DRACILM model is the most appropriate model for assessing specific vulnerability to nitrate pollution in the West Liaohe plain; the class of specific vulnerability approached real vulnerability conditions, showing that DRACILM produces more reasonable and reliable results. The vulnerability maps could assist planners and government decision-makers with preliminary investigations into planning water protection projects or 
establishing management scenarios for water resource quality. Specific measures were taken by the central government in its $13^{\text {th }}$ Five-Year Plan to prevent some activities from causing groundwater pollution in highly vulnerable areas.

Due to the large study area and research fund limits, which led to the relatively low precision, our research did not include a special study like the field, and the microbial samples were not collected, the denitrification cannot be determined. Therefore, the limitations of this study cannot accurately characterize the chemical process of nitrogen and cannot determine the "dynamic" changes of the vulnerability. The study that comprehensively confirmed the intrinsic and special vulnerability of the West Liaohe Plain lays a solid foundation for future research, which can focus on changing nitrogen's impact on the "dynamic" vulnerability.

\section{Acknowledgements}

This study was supported by the Public Welfare Geological Survey Projects of China Geological Survey Bureau (No. 1212011220980) and The National Natural Science Fund (No. 41602247). The authors would like to thank the journal editors and reviewers for their comments, which helped to improve the paper considerably. We are also thankful to the staff at the Hydrogeology and Environmental Geology Laboratory of Shenyang Center Geological Survey.

\section{References}

1. SHRESTHA S., SEMKUYU D.J., PANDEY V.P. Assessment of groundwater vulnerability and risk to pollution in Kathmandu Valley, Nepal.Science of The Total Environment, 556, 23, 2016.

2. ALLER L., BENNET T., LEHR J.H., PETTY R.J.DRASTIC: A Standardized System for Evaluating Ground Water Pollution Potential using Hydro Geologic Settings, U.S. EPA, 1987.

3. FOSTER S., HIRATA R., GOMES D., DELIA M., PARIS M. Groundwater Quality Protection. A guide for water utilities, municipal authorities, and environmental agencies. The World Bank. Washington, D.C, 2002.

4. KAZAKIS N., VOUDOURIS K.S. Groundwater vulnerability and pollution risk assessment of porous aquifers to nitrate: Modifying the DRASTIC method using quantitative parameters. Journal of Hydrology, 525, 13, 2015.

5. BAALOUSHA H.M. Groundwater vulnerability mapping of Qatar aquifers. Journal of African Earth Sciences, 124, 75, 2016.

6. MUHAMMAD A.M., TANG Z., DAWOOD A.S., EARL B. Evaluation of local groundwater vulnerability based on DRASTIC index method in Lahore, Pakistan. Geofísica Internacional, 54 (1), 153, 2014.

7. HUAN H., WANG J., TENG Y. Assessment and validation of groundwater vulnerability to nitrate based on a modified DRASTIC model: a case study in jilin city of northeast China. Science of the Total Environment, 440, 14-23, 2012.
8. AL-HANBALI A., KONDOH A. Groundwater vulnerability assessment and evaluation of human activity impact (HAI) within the Dead Sea groundwater basin, Jordan. Hydrogeology Journal, 16 (3), 499, 2008.

9. FARJAD B, MOHAMED T.A., WIJESEKARA N., PIRASTEH S., SHAFRI H.M. Groundwater intrinsic vulnerability and risk mapping. Proceedings of the ICE Water Management, 165 (8), 441, 2012.

10. MIMI Z.A., MAHMOUD N., MADI M.A. Modified DRASTIC assessment for intrinsic vulnerability mapping of karst aquifers: a case study. Environmental Earth Sciences, 66 (2), 447, 2011.

11. LASAGNA M., DELUCAD A., FRANCHINO E. The role of physical and biological processes in aquifers and their importance on groundwater vulnerability to nitrate pollution. Environmental Earth Sciences,75 (11), 1, 2016.

12. PISCIOTTAA A., CUSIMANOB G., FAVARAA R. Groundwater nitrate risk assessment using intrinsic vulnerability methods: A comparative study of environmental impact by intensive farming in the Mediterranean region of Sicily, Italy. Journal of Geochemical Exploration, 156, 89, 2015.

13. CHENINI S., ZGHIBI A., KOUZANA L. Hydrogeological investigations and groundwater vulnerability assessment and mapping for groundwater resource protection and management: State of the art and a case study. Journal of African Earth Sciences, 109, 11, 2015.

14. SAHOO S., DHAR A., KAR A. Environmental vulnerability assessment using Grey Analytic Hierarchy Process based model. Environmental Impact Assessment Review, 56, 145, 2016.

15. GHOSH T., KANCHAN R. Aquifer vulnerability assessment in the Bengal alluvial tract, India, using GIS based DRASTIC model. Modeling Earth Systems and Environment, 2 (3), 153, 2016.

16. SHUKLA S., MOSTAGHIMI S., SHANHOLT V.O., COLLINS M.C., ROSS B.B. A county-level assessment of ground water contamination by pesticides. Groundwater Monitoring \& Remediation, 20 (1), 104, 2000.

17. MOHAMMADI K., NIKNAM R., MAJD V.J. Aquifer vulnerability assessment using GIS and fuzzy system: a case study in Tehran-Karaj aquifer, Iran. Environmental Geology, 58 (2), 437, 2009.

18. WANG J., HE J., CHEN H. Assessment of groundwater contamination risk using hazard quantification, a modified DRASTIC model and groundwater value, Beijing Plain, China. Science of the Total Environment, 432, 216, 2012.

19. LATHAMANIR., JANARDHANAMR., MAHALINGAM B., SURESHA S. Evaluation of Aquifer Vulnerability Using Drastic Model and GIS: A Case Study of Mysore City, Karnataka, India. Hydrogeol. J, 4, 1031, 2015.

20. LIGGETT J., GILCHRIST A., DENNY C., PURDY R., MUNRO L., LAPCEVIC P., CARMICHAEL V., EARLE S., TALWAR S., JOURNEAY J.M. Technical summary of intrinsic vulnerability mapping methods in the regional districts of Nanaimo and Cowichan valley. Geological Survey of Canada, Open File 6168, 64, 2010.

21. SENTHILKUMAR P., NITHYA J., BABU S.S. Assessment of Groundwater Vulnerability in Krishnagiri District, Tamil Nadu, India Using DRASTIC Approach. International Journal of Innovative Research in Science, Engineering and Technology, 3 (3), 253, 2014.

22. ERSOY A.F., GÜLTEKIN F. DRASTIC-based methodology for assessing groundwater vulnerability in the Gümüşhacıköy and Merzifon basin (Amasya, Turkey). Earth sciences research journal, 17 (1), 33, 2013. 
23. SAIDI S., BOURI S., BEN D.H. Groundwater vulnerability and risk mapping of the Hajeb-jelma aquifer(Central Tunisia) using a GIS-based DRASTIC model. Environmental Earth Sciences, 59 (7), 1579, 2010.

24. OUEDRAOGO I., DEFOURNY P., VANCLOOSTER M. Mapping the groundwater vulnerability for pollution at the pan African scale. Science of the Total Environment, 544, 939, 2016.

25. MUSEKIWA C., MAJOLA K. Groundwater vulnerability map for South Africa. South African Journal of Geomatics, 2 (2), 152, 2013

26. CHANDOUL I.R., BOUAZIZ S., DHIA H.B. Groundwater vulnerability assessment using GIS-based DRASTIC models in shallow aquifer of Gabes North (South East Tunisia). Arabian Journal of Geosciences, 8 (9), 7619, 2015.

27. ROSEN L. A study of the DRASTIC methodology with emphasis on Swedish conditions. Ground Water, 32, 278, 1994.

28. AYDI W., SAIDI S., CHALBAOUI M., CHAIBI S., DHIA H.B. Evaluation of the Groundwater Vulnerability to Pollution Using an Intrinsic and a Specific Method in a GIS Environment: Application to the Plain of Sidi Bouzid (Central Tunisia). Arabian Journal for Science and Engineering, 38 (7), 1815, 2013.

29. MCLAY C., DRAGDEN R., SPARLING G., SELVARAJAH N. Predicting groundwater nitrate concentrations in a region of mixed agricultural land use: a comparison of three approaches. Environ Pollut, 115, 191, 2001.

30. PANAGOPOULOS G.P., ANTONAKOS A.K., LAMBRAKIS N.J. Optimization of the DRASTIC method for groundwater vulnerability assessment via the use of simple statistical methods and GIS. Hydrogeology, 14 (1), 894, 2006.

31. FIJANI E., NADIRI A.A., MOGHADDAM A.A., TSAI T.C., DIXON B. Optimization of DRASTIC method by supervised committee machine artificial intelligence to assess groundwater vulnerability for Maragheh-Bonab plain aquifer, Iran. Journal of Hydrology, 503, 89, 2013.

32. MISHIMA Y., TAKADA M., KITAGAWA R. Evaluation of intrinsic vulnerability to nitrate contamination of groundwater: appropriate fertilizer application management. Environmental Earth Sciences, 63 (3), 571, 2011.

33. BAGHAPOUR M.A., NOBANDEGANI A.F., TALEBBEYDOKHTI N., BAGHERZADEH S., NADIRI A.A., GHAREKHANI M., CHITSAZAN N. Optimization of DRASTIC method by artificial neural network, nitrate vulnerability index, and composite DRASTIC models to assess groundwater vulnerability for unconfined aquifer of Shiraz Plain, Iran. Journal of Environmental Health Science and Engineering, 14 (1), 13, 2005.

34. YANG L., YANG Y., FENG Z., ZHENG Y. Effect of maize sowing area changes on agricultural water consumption from 2000 to 2010 in the West Liaohe Plain, China. Journal of Integrative Agriculture, 15 (6), 1407, 2016.

35. BOZ B., GUMIERO B. Nitrogen removal in an afforested riparian zone: the contribution of denitrification processes. Hydrobiologia, 774 (1), 167, 2016.
36. U.S. Environmental Protection Agency. Environmental indicator of water quality in the United States: Washington, D.C., Office of Water, EPA 841-R-96-002, EPA, Washington, DC, 1996.

37. ENTEZARI M., YAMANI M., AGHDAM M.J. Evaluation of intrinsic vulnerability, hazard and risk mapping for karst aquifers, Khorein aquifer, Kermanshah province: a case study. Environmental Earth Sciences, 75 (5), 1, 2016

38. ALRAWABDEH A.M., ALANSARI N.A., ALTAANI A.A., KNUTSSON S. A GIS-Based Drastic Model for Assessing Aquifer Vulnerability in Amman-Zerqa Groundwater Basin, Jordan. Journal of Clinical Oncology Official Journal of the American Society of Clinical Oncology, 5 (5), 490-, 2013.

39. PORCEL R.A., SCHUTH C., LEONGOMEZ H.D., HOPPE A., LEHNE R. Land-Use Impact and Nitrate Analysis to Validate DRASTIC Vulnerability Maps Using a GIS Platform of Pablillo River Basin, Linares, N.L., Mexico. International Journal of Geosciences, 5 (12), 1468, 2014.

40. LAKE L.R., LOVETT A.A., HISCOCK K.M. BETSON M., FOLEY A., SÜNNENBERG G., EVERS S., FLETCHER S. Evaluating factors influencing groundwater vulnerability to nitrate pollution: developing the potential of GIS. J. Environ. Manage, 328 (68), 315, 2003.

41. BRYMAN A., CRAMER D. Quantitative Data Analysis with SPSS for Windows. Routledge, London, 1997.

42. DHAMI I., DENG J., STRAGER M., CONLEY J. Suitability-sensitivity analysis of nature-based tourism using geographic information systems and analytic hierarchy process. Journal of Ecotourism, 1, 1, 2016.

43. NAPOLITANO P., FABBRI A.G. Single-parameter sensitivity analysis for aquifer vulnerability assessment using DRASTIC and SINTACS. Application of Geographic Information Systems in Hydrology and Water Resources Management, 235, 559, 1996.

44. BABIKER I.S., MOHAMED A.A., MOHAMED, H.T., KATO K. A GIS-based DRASTICmodel for assessing aquifer vulnerability in Kakamigahara Heights, Gifu Prefecture, central Japan. Sci. Total Environ, 345 (1-3), 127, 2005.

45. LI R., MERCHANT J.W. Modeling vulnerability of groundwater to pollution under future scenarios of climate change and biofuels-related land use change: A case study in North Dakota, USA. Science of the Total Environment. 447, 32, 2013.

46. JANG C.S., LIN C.W., LIANG C.P., CHEN J.S. Developing a reliable model for aquifer vulnerability. Water Research, 30 (1), 175, 2016

47. STIGTER T., ALMEIDA P., CARVALHO D.A., RIBEIRO L. Evaluation of an intrinsic and a specific vulnerability assessment method in comparison with groundwater salinisation and nitrate contamination levels in two agricultural regions in the south of Portugal. Hydrogeol J, 14 (3), 79, 2006. 